\title{
STUDIES ON DIGITALIS IN AMBULATORY CARDIAC PATIENTS
}

\author{
II. The Elimination of Digitalis in Man
}

BY HARRY GOLD AND ARTHUR C. DEGRAFF

(From the Third Medical (New York University) Division of Bellevue Hospital and Department of Pharmacology of Cornell University Medical College)

(Received for publication September 14, 1928)

A study of the rate of elimination of digitalis in normal animals in terms of persistence of action was published by one of us (1) in 1923. The curves invariably show that after a single large injection, elimination is very rapid at first and then slower, i.e., as the quantity of digitalis in the body diminishes, that eliminated daily also diminishes. This was demonstrated in another way as seen from the following example taken from that paper: each of several animals received a single intravenous injection of 75 per cent of the average fatal dose of a given tincture of digitalis. In 24 hours, the average quantity eliminated was 45 per cent of a fatal dose. If the capacity for elimination of the drug could be expressed as a fixed quantity per day -45 per cent of a fatal dose for this specimen - an animal receiving a daily intravenous injection of 50 per cent of a fatal dose of this tincture would require about 20 such daily doses to cause death, and an animal receiving a daily injection of 25 per cent of a fatal dose of this specimen would never accumulate sufficient digitalis in the body to cause death. As a matter of fact, two animals that had received daily injections of $\mathbf{5 0}$ per cent of a fatal dose of this tincture died after the fourth and fifth dose, respectively, and two animals that had received daily injections of 25 per cent of a fatal dose died after the tenth and eleventh injection respectively. The conclusion necessarily follows that the amount of digitalis eliminated daily depends upon the amount of the drug in the body, and that in all probability, only a percentage of that present can be eliminated in a unit of time.

The curve of digitalis elimination is rendered complex by the presence 
of different fractions in the drug, some of which are slowly, and others very rapidly eliminated $(1,2,3)$. Hence, after full digitalis effects have been produced, the curve of elimination would be expected to vary, depending upon whether these effects have been induced by a single large dose or daily repeated small doses.

A very elementary pharmacologic principle is involved, but it appears to have been entirely ignored in the clinical studies of the drug. In 1919, Pardee (4) published some experiments on the elimination of digitalis in man, with a method similar to the one in the above studies except that vomiting was usually employed as the end point. He produced full digitalization fairly rapidly in a series of patients and after varying intervals, these patients again received digitalis, sufficient in several days to reinduce the vomiting. The quantity of the drug required for the second course divided by the interval in days between the two toxic end points yielded a number that was taken to represent the amount of digitalis that disappears from the body daily. The average with the specimen of the tincture he employed was about $1.4 \mathrm{cc}$. per day with variations from about 0.81 to $1.9 \mathrm{cc}$. Among other conclusions, he stated that the amount of digitalis disappearing daily did not appear to depend upon the quantity in the body. In a subsequent paper (5) Pardee elaborated on the practical application of these experiments. Here he again stated that the average patient excretes about 0.13 gram of digitalis in a day and that after initial full digitalization (to the point of minor toxic symptoms), the daily excretion dose "can and must be given to maintain the digitalis effect." $\mathrm{He}$ cited instances indicating that if a patient were to receive only the daily excretion dose without initial full digitalization, the drug would never reach an effective concentration in the body because it would be "excreted as fast as it is taken in."

We have been studying the various phases of the question of the elimination of digitalis and the duration of its effects in man. It appeared to us extremely improbable that the rate of disappearance of digitalis from the body in man can be expressed in the form of a straight line-about 0.13 gram daily; also its corollary, that the amount eliminated in a day by a given patient bears no relation to the amount in the body. A conclusion so at variance with our knowledge of the general behavior of drugs in the animal organ- 
ism and with the evidence obtained from animal experiments concerning digitalis elimination, caused us to question the adequacy of the method employed to determine the daily rate of disappearance of digitalis in man. A number of experiments carried out in the clinic appears to us to leave little doubt that in essentials, man does not differ from other animals in the elimination of digitalis. They show that the daily excretion dose is a misconception, that the amount of digitalis eliminated in a day cannot be stated as a given quantity under all conditions, but varies with the amount of the drug present in the body. These experiments are the subject of the present report.

The studies have been carried out upon ambulatory cardiac patients with auricular fibrillation, because in these the onset and disappearance of digitalis effects can be established with greater precision. The type of medical and social service organization of this clinic' and the personal contact established between the patients and the staff, have made it possible to carry out observations over long periods of time with results as reliable, within limits, as those carried out on a hospital ward in this type of work. Patients who could not be depended upon to comply strictly with orders were excluded from the study. Digitalis was employed in a manner similar to that described in a previous paper (6). Compressed tablets of dried digitalis leaf standardized by the cat unit method, were dispensed to the patients and the daily amount ordered to be taken in a single dose.

The ventricular rate was used to indicate the intensity of digitalis action and this was particularly satisfactory in that group of patients who are in this respect very sensitive to the drug, in whom marked changes in the ventricular rate occur readily when the drug is given or withheld. In all instances the work and exercise during a given period were inquired about so as to exclude those cases in which it could not be stated with a fair degree of certainty that there was neither more exertion nor more rest to account for the changes in the rate attributed to the withdrawal or administration of digitalis. The apex rate was counted by the stethoscope under fairly uniform conditions with the patient sitting or lying after a period of rest. With these precautions, the occasional variability is far less striking than the general uniformity

${ }^{1}$ The Adult Cardiac Clinic of Bellevue Hospital. 
of the record of the heart rate from week to week in suitable cases under constant medication. Nevertheless, significance was attached to only marked changes in the rate and when there were associated conditions that served as a check.

Two assumptions formed the basis of the present study: first, that if a given degree of depression of conduction has been produced by digitalis and this effect is not increased in intensity by the administration of a fixed daily dose for weeks or months and no toxic symptoms

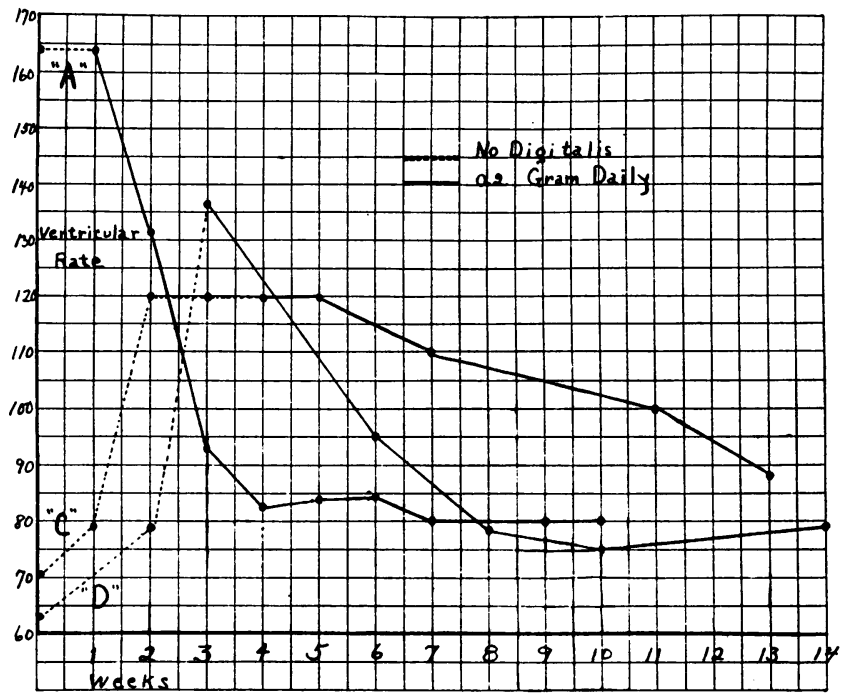

CharT 1. Patient E. P.; age 23; rheumatic heart disease, mitral stenosis and insufficiency, aortic stenosis and insufficiency, enlarged heart, auricular fibrillation.

occur, the patient is capable of eliminating that dose; second, if a fixed daily dose of digitalis produces progressively increasing depression of conduction, that dose is greater than the patient is eliminating. Experiments were performed to determine whether it be possible to produce progressively increasing digitalis effects in a patient who had had no digitalis, with a fixed daily dose of the drug which the same patient is capable of eliminating under other conditions. The observations made in four of the experiments on two patients have been charted and serve to illustrate the general results. 
Patient E. P. (chart 1) appeared at the clinic with a ventricular rate of 164; he had never had any digitalis. He was permitted to go one week longer without the drug and the rate remained unchanged. He was then given 0.2 gram daily of specimen "A." The rate gradually decreased, reached a level of about 80 by the third week, and remained constant during a subsequent period of observation of six weeks during which the same dose was taken. Several months later, this patient was under the influence of digitalis and the ventricular rate was 64 . The drug was withheld for a period of three weeks and the ventricular rate increased to 136 . He was then given 0.2 gram daily of specimen "D." The ventricular rate again diminished gradually and reached a level of about 80 , at which it remained for several weeks with the same daily dose of the drug. This was repeated at a subsequent time with specimen "C."

Since progressively increasing intensity of the digitalis effect mentioned (depression of conduction) during the administration of a fixed daily dose of the drug is taken as evidence that the patient is receiving more digitalis than he is eliminating, it must be assumed that when this patient had no digitalis in the body, he was incapable of eliminating the 0.2 gram that was given daily, but after he had accumulated a certain portion of the 4.2 grams that had been given in a period of twenty-one days, he now was eliminating 0.2 gram daily.

It is also interesting to note that the curves are essentially similar with specimens " $\mathrm{A}$ " and " $\mathrm{D}$ " which are very similar in activity, the former $79 \mathrm{mgm}$., the latter $87 \mathrm{mgm}$. to the cat unit. With specimen " $\mathrm{C}$ " it took more time to accumulate sufficient digitalis to produce the results as might have been anticipated from the fact that it was a poor specimen with an activity of $140 \mathrm{mgm}$. to the cat unit.

In patient J. R. (chart 2), after digitalis had been given for several months, the drug was withheld and the ventricular rate gradually increased during a period of twelve weeks to 120 . The patient then received 0.2 gram daily of specimen " $D$ " and the rate gradually diminished until it reached a level that was maintained for several weeks. The dose was increased to $\mathbf{0 . 2 5}$ gram daily for fourteen weeks (98 doses) and the rate remained unchanged. This indicates that a patient who was able to eliminate 0.25 gram daily after considerable digitalis had accumulated, was unable to eliminate even 0.2 gram daily 
during the early period of the administration of the latter dose when there was none of the drug in the body at the beginning.

Thirty-four satisfactory tests were carried out on a series of twentythree patients. These patients are classified in table 1 and the observations are summarized in table 2. A large number of experiments were performed the results of which have not been included in the table because the daily dose of digitalis selected in those instances was either too small or too large for a suitable demonstration of the principle. Five different specimens of dried digitalis leaves were employed. These had the following activity in terms of milligrams of the leaf per cat unit: "A"-79; "C"-140; "D"-87; "E"-100; "F"-65. Wherever possible, tests were repeated in a given patient

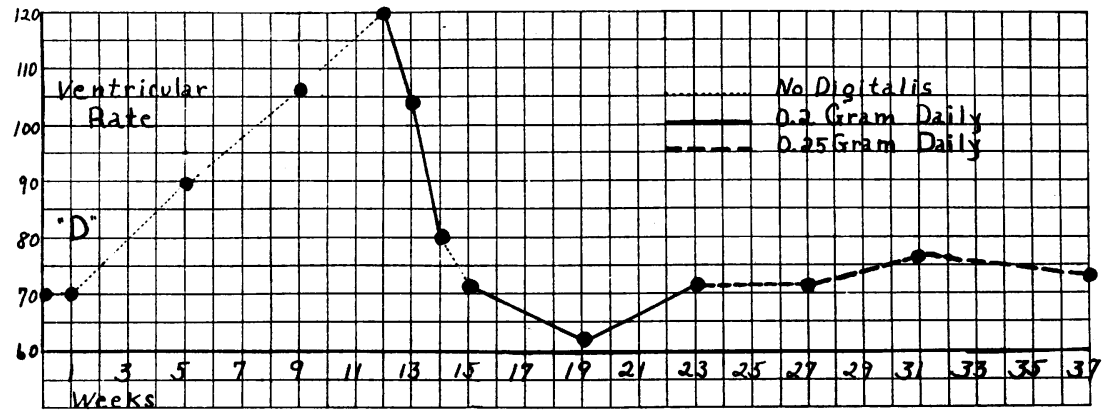

Chart 2. Patient J. R.; age 49; heart disease of unknown origin, enlarged heart, auricular fibrillation.

with one or more specimens of the drug. The results show uniformly that when the drug was withheld the ventricular rate became rapid, and when the administration of a fixed daily dose of the drug was started, progressively increasing effects occurred for a time, then a level was reached which was maintained unchanged by the same daily dose for a number of weeks. Several observations were recorded in each period in which the drug was withheld; when the increase in the ventricular rate began it was progressive and frequently a pulse deficit appeared. Varying degrees of symptoms of failure often occurred which were improved by the administration of the drug. There were no toxic symptoms in any of these cases. In those instances in which the new level was recorded after the first period of 
TABLE 1

Showing the clinical classification of the patients used for the tests that are summarized in table 2

\begin{tabular}{|c|c|c|c|c|c|c|}
\hline \multirow{2}{*}{$\begin{array}{c}\text { Number } \\
\text { of } \\
\text { patient }\end{array}$} & \multirow{2}{*}{ Sex } & \multirow{2}{*}{ Age } & \multirow{2}{*}{ Weight } & \multicolumn{2}{|r|}{ Diagnosis } & \multirow{2}{*}{$\begin{array}{l}\text { Func- } \\
\text { tional } \\
\text { classifica- } \\
\text { tion* }\end{array}$} \\
\hline & & & & Etiologicol & Anatomical & \\
\hline & & & kgm. & & & \\
\hline 994 & M. & 27 & 65.9 & Rheumatic & $\begin{array}{l}\text { Enlarged heart, mitral stenosis } \\
\text { and insufficiency, aortic } \\
\text { stenosis and insufficiency }\end{array}$ & II-a \\
\hline 1261 & M. & 39 & 70.9 & Rheumatic & $\begin{array}{l}\text { Enlarged heart, mitral stenosis } \\
\text { and insufficiency }\end{array}$ & II-b \\
\hline 65 & M. & 56 & 66.3 & Rheumatic & $\begin{array}{l}\text { Enlarged heart, mitral stenosis } \\
\text { and insufficiency, aortic } \\
\text { stenosis and insufficiency }\end{array}$ & III \\
\hline 1119 & M. & 58 & 100 & Unknown & Enlarged heart & II-b \\
\hline 1254 & M. & 48 & 67.2 & Rheumatic & $\begin{array}{l}\text { Enlarged heart, mitral stenosis } \\
\text { and insufficiency }\end{array}$ & II-b \\
\hline 1369 & M. & 58 & 98.6 & Arteriosclerotic & Enlarged heart & II-b \\
\hline 1388 & M. & 67 & 60.0 & Arteriosclerotic & Enlarged heart & II-b \\
\hline 1715 & F. & 51 & 50.0 & Arteriosclerotic & Enlarged heart & II-b \\
\hline 124 & F. & 35 & 63.6 & Rheumatic & $\begin{array}{l}\text { Enlarged heart, mitral stenosis } \\
\text { and insufficiency }\end{array}$ & II-b \\
\hline 594 & F. & 58 & 61.8 & Arteriosclerotic & Enlarged heart & II-b \\
\hline 1768 & M. & 35 & 61.3 & Rheumatic & $\begin{array}{l}\text { Enlarged heart, mitral stenosis } \\
\text { and insufficiency }\end{array}$ & II-b \\
\hline 1181 & M. & 54 & 62.2 & Unknown & Enlarged heart & II-b \\
\hline 948 & M. & 18 & 40.9 & Rheumatic & $\begin{array}{l}\text { Enlarged heart, mitral stenosis } \\
\text { and insufficiency, adhesive } \\
\text { pericarditis }\end{array}$ & II-b \\
\hline 1519 & F. & 38 & 70.0 & Rheumatic & $\begin{array}{l}\text { Enlarged heart, mitral stenosis } \\
\text { and insufficiency }\end{array}$ & II-b \\
\hline 1201 & M. & 46 & 70.4 & Unknown & Enlarged heart & II-a \\
\hline 629 & M. & 51 & 71.3 & Unknown & $\begin{array}{l}\text { Enlarged heart, mitral stenosis } \\
\text { and insufficiency }\end{array}$ & II-a \\
\hline 1848 & F. & 36 & 60.0 & Rheumatic & $\begin{array}{l}\text { Enlarged heart, mitral stenosis } \\
\text { and insufficiency }\end{array}$ & II-b \\
\hline 1858 & F. & 38 & 60.0 & Unknown & Enlarged heart & II-b \\
\hline 1728 & F. & 60 & 83.6 & Unknown & Enlarged heart & II-b \\
\hline 679 & M. & 32 & 55.9 & Unknown & $\begin{array}{l}\text { Enlarged heart, mitral stenosis } \\
\text { and insufficiency }\end{array}$ & II-b \\
\hline 1892 & F. & 36 & 52.7 & Unknown & Enlarged heart & II-b \\
\hline 1855 & F. & 41 & 90.9 & Unknown & $\begin{array}{l}\text { Enlarged heart, mitral stenosis } \\
\text { and insufficiency }\end{array}$ & II-b \\
\hline 1615 & M. & 67 & 86.3 & Arteriosclerotic & Enlarged heart, aortitis & II-a \\
\hline
\end{tabular}

* (II-a) able to carry on slightly diminished physical activity; (II-b) able to carry on greatly diminished physical activity; (III) symptoms of heart failure at rest. 
TABLE 2

Showing a digitalis effect progressively increasing in intensity with a fixed daily dose of the drug which the patient at a given stage eliminates

\begin{tabular}{|c|c|c|c|c|}
\hline Number of patient & $\begin{array}{l}\text { Number of test and } \\
\text { specimen of digitalis }\end{array}$ & Daily dose & Number of days & Ventricular rate \\
\hline \multirow{27}{*}{994} & \multirow{11}{*}{ 1-A } & grams & & \\
\hline & & \multicolumn{2}{|c|}{ Never had digitalis } & 164 \\
\hline & & 0 & 7 & 164 \\
\hline & & 0.2 & 7 & 130 \\
\hline & & 0.2 & 7 & 93 \\
\hline & & 0.2 & 7 & 82 \\
\hline & & 0.2 & 7 & 84 \\
\hline & & 0.2 & 7 & 84 \\
\hline & & 0.2 & 7 & 80 \\
\hline & & 0.2 & $7^{\circ}$ & 80 \\
\hline & & 0.2 & 14 & $\dot{80}$ \\
\hline & \multirow{8}{*}{$2-C$} & 0 & 28 & 120 \\
\hline & & 0.2 & 7 & 120 \\
\hline & & 0.2 & 7 & 110 \\
\hline & & 0.2 & 28 & 100 \\
\hline & & 0.2 & 14 & 88 \\
\hline & & 0.25 & 7 & 88 \\
\hline & & 0.25 & 21 & 86 \\
\hline & & 0.25 & 14 & 74 \\
\hline & \multirow{4}{*}{ 3-D } & 0 & 21 & 136 \\
\hline & & 0.2 & 21 & 95 \\
\hline & & 0.2 & 28 & 76 \\
\hline & & 0.2 & 28 & 80 \\
\hline & \multirow{4}{*}{$1-\mathrm{C}$} & 0 & 21 & 108 \\
\hline & & 0.2 & 21 & 70 \\
\hline & & 0.2 & 28 & 76 \\
\hline & & 0.2 & 21 & 72 \\
\hline \multirow{7}{*}{679} & \multirow{7}{*}{$2-\mathrm{E}$} & 0 & 35 & 120 \\
\hline & & 0.1 & 35 & 110 \\
\hline & & 0.13 & 21 & 94 \\
\hline & & 0.13 & 28 & 94 \\
\hline & & 0.13 & 28 & 74 \\
\hline & & 0.13 & 28 & 80 \\
\hline & & 0.13 & 21 & 74 \\
\hline \multirow{6}{*}{1261} & \multirow{6}{*}{$1-\mathrm{F}$} & 0 & 28 & 96 \\
\hline & & 0.2 & 35 & 76 \\
\hline & & 0.2 & 42 & 82 \\
\hline & & 0.2 & 42 & 84 \\
\hline & & 0.2 & 42 & 82 \\
\hline & & 0.2 & 42 & 78 \\
\hline
\end{tabular}


TABLE 2-Continued

\begin{tabular}{|c|c|c|c|c|}
\hline Number of patient & $\begin{array}{l}\text { Number of test and } \\
\text { specimen of digitalis }\end{array}$ & Daily dose & Number of days & Ventricular rate \\
\hline 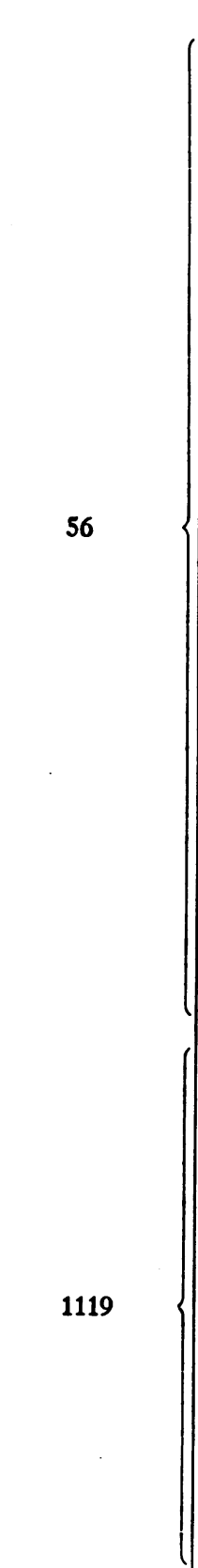 & $\begin{array}{l}\text { 3-E } \\
\text { 4-E }\end{array}$ & 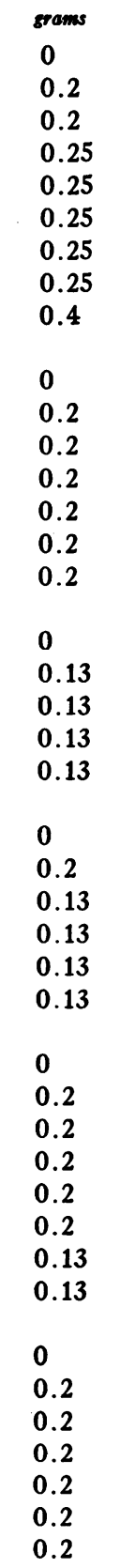 & 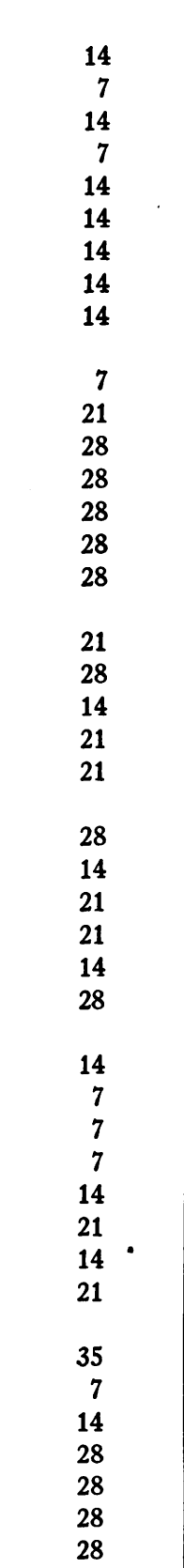 & 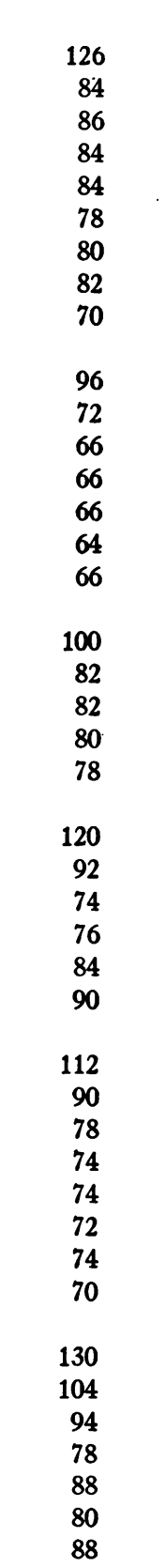 \\
\hline
\end{tabular}


TABLE 2-Continued

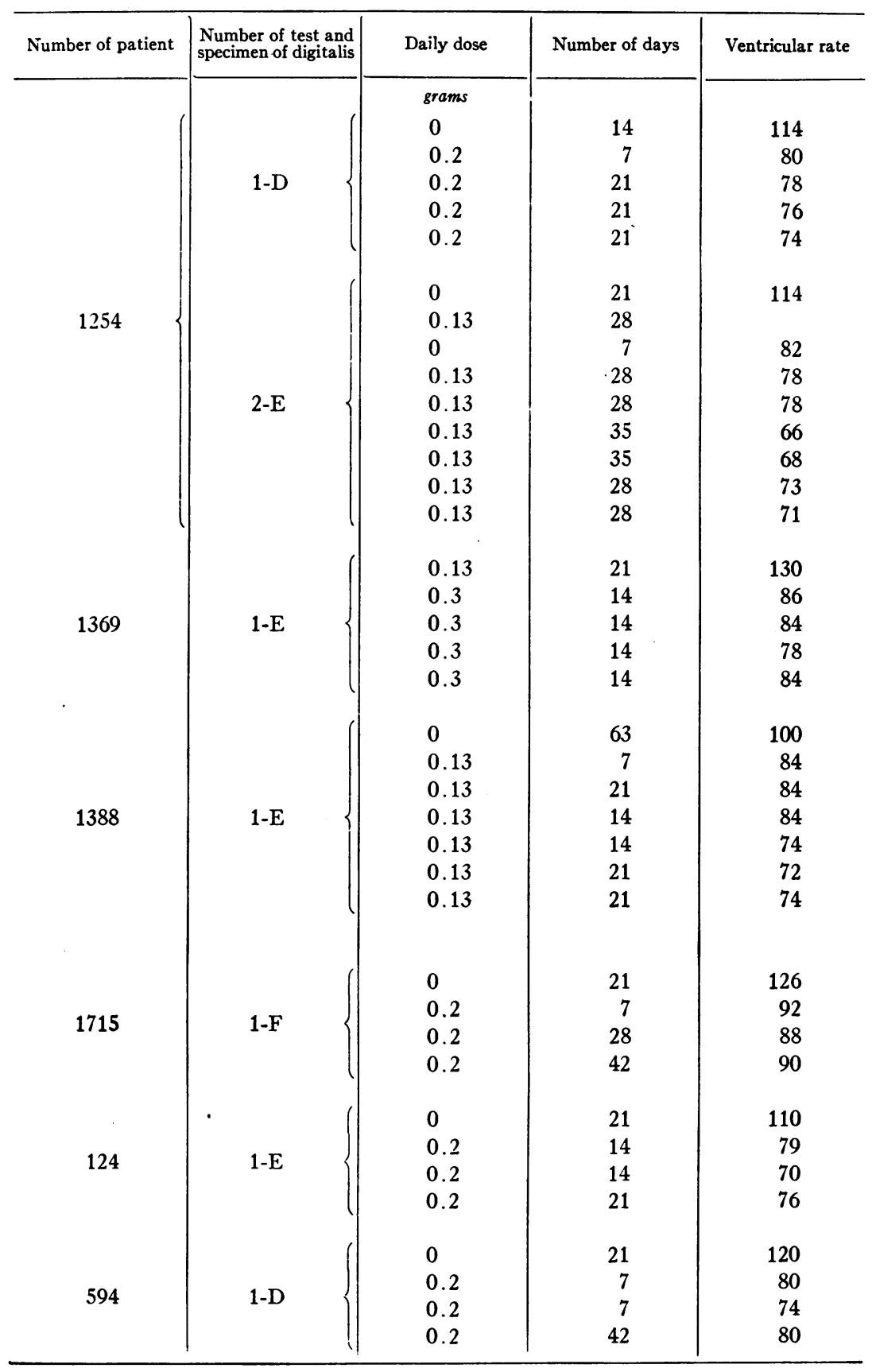




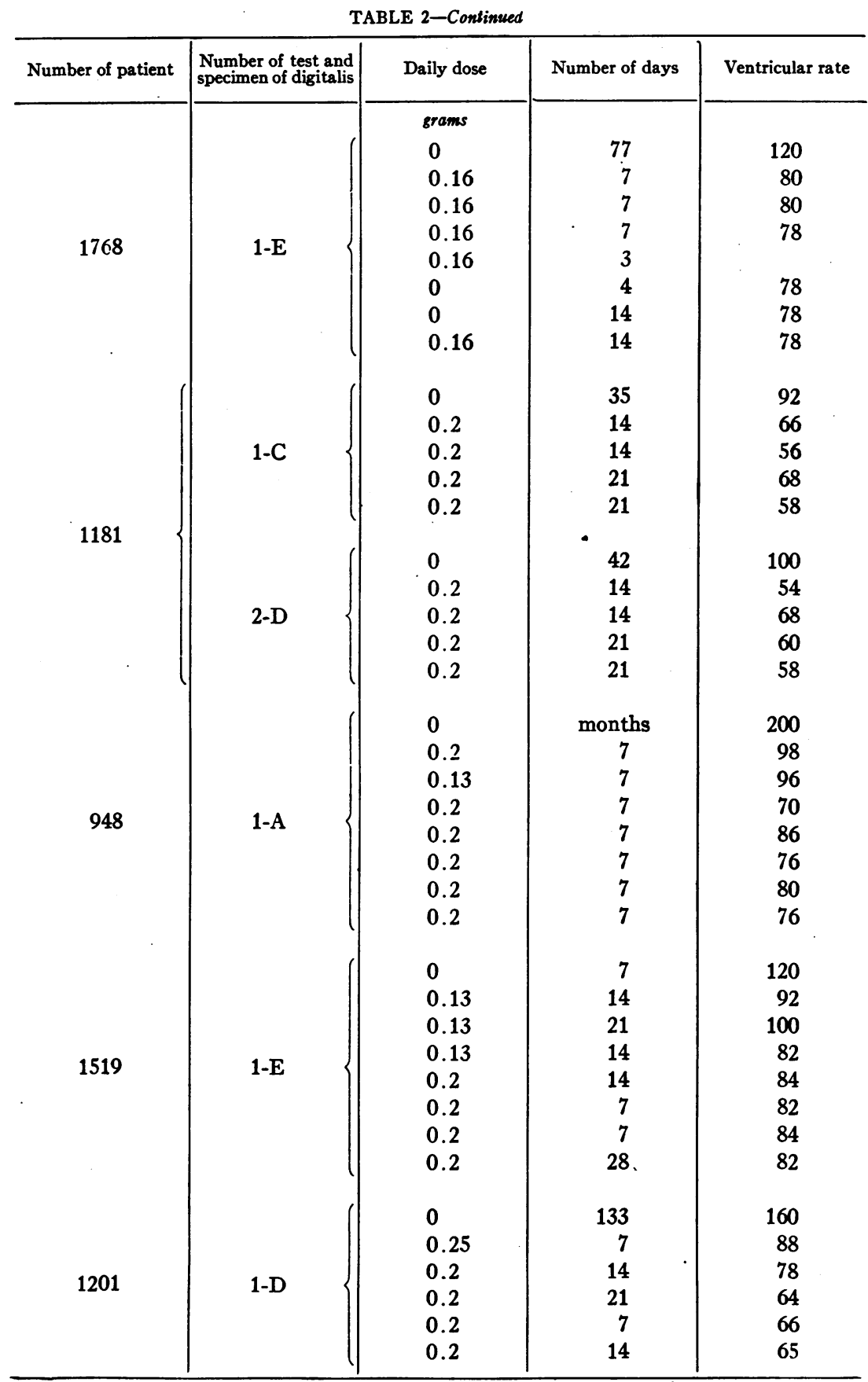


TABLE 2-Contimued

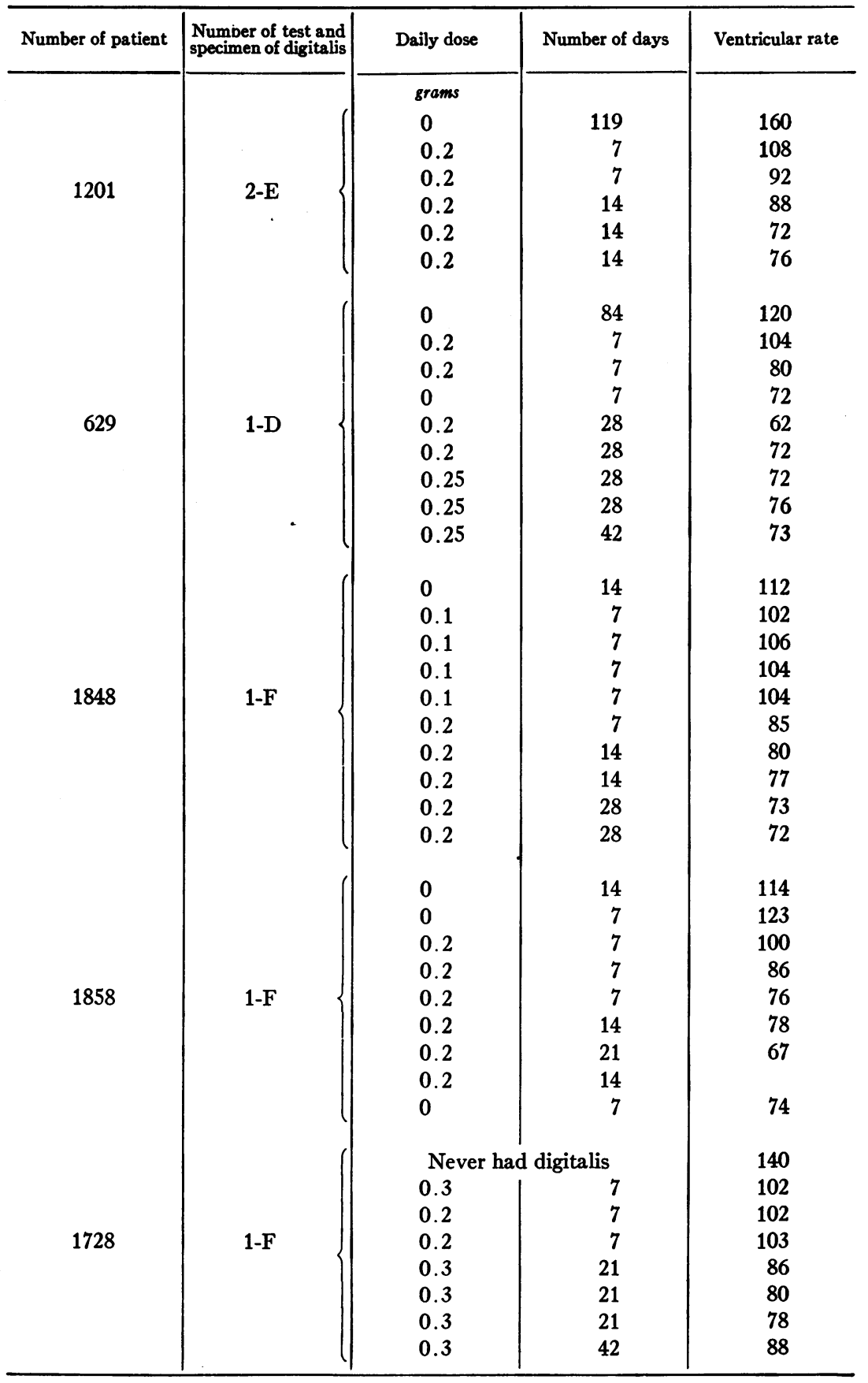

624 
HARRY GOLD AND ARTHUR C. DEGRAFF

TABLE 2-Concluded

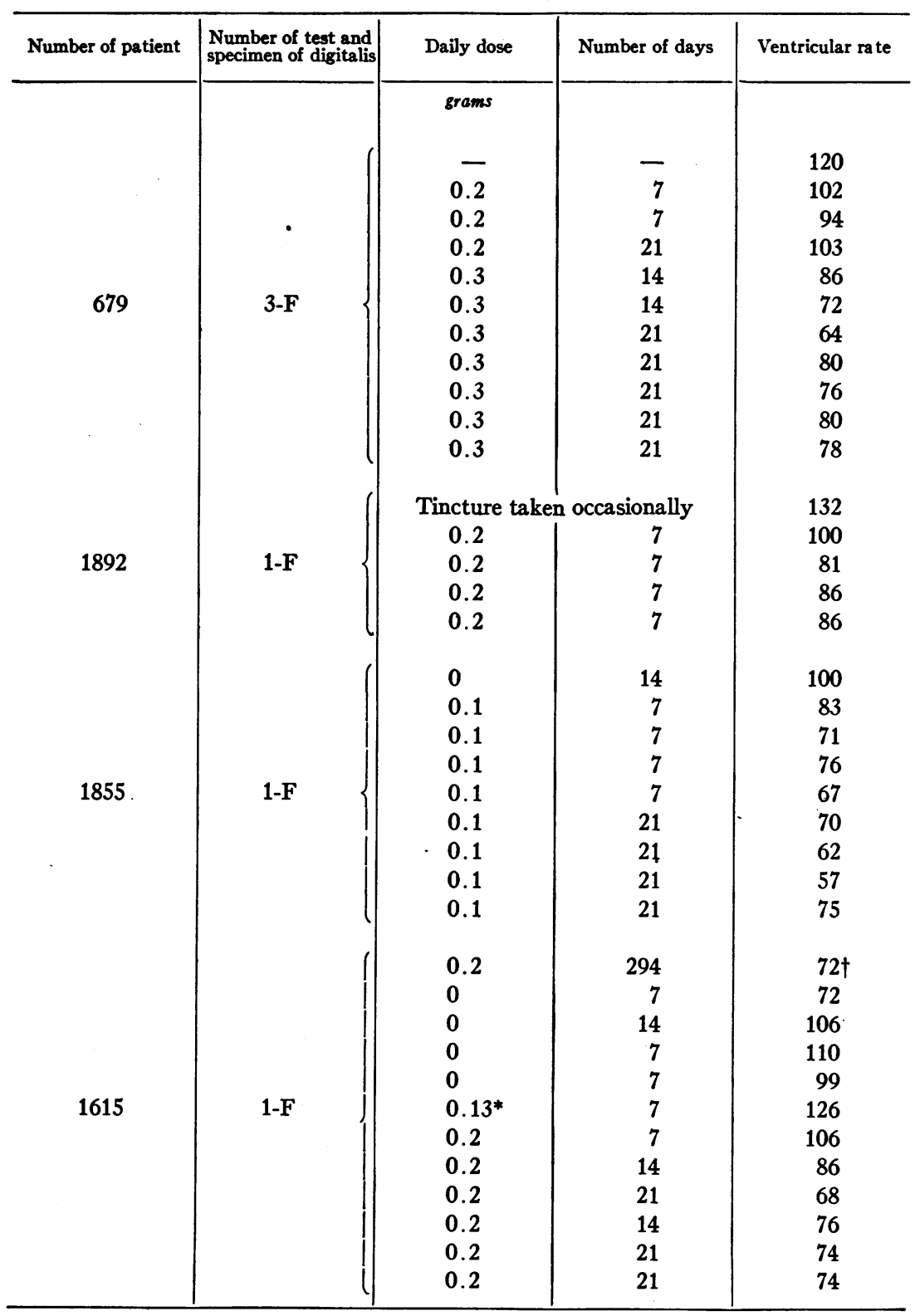

* Specimen E.

$\dagger$ Average of 11 records. 
digitalis medication, it was considered fairly certain that the results obtained were not produced by only one dose of the drug, but were the cumulative effects of several doses.

Other interesting data contained in this table will be discussed in a subsequent paper dealing with a study of digitalis dosage and persistence of effects.

\section{SUMMARY AND CONCLUSIONS}

We have studied the curve of elimination of digitalis in man in terms of persistence of action and in the present paper we have set forth evidence showing that the idea that patients excrete about 0.13 gram of digitalis in a day under widely varying conditions, is incorrect. If a patient has 1.3 grams of digitalis in the body, he may eliminate, let us say, 0.13 gram (10 per cent) in 24 hours, but if he has only 0.13 gram in the body at the start, he may eliminate only 0.013 gram (10 per cent) in 24 hours. These figures are purely arbitrary and intended simply to illustrate the conclusions based upon the evidence presented, that a patient does not eliminate a fixed quantity of digitalis, but a percentage of that which is present in the body at any time.

The authors wish to express their obligation to Dr. John Wyckoff for generous coöperation in these studies.

\section{BIBLIOGRAPHY}

1. Gold, H., Arch. Int. Med., 1923, xxxii, 779. Digitalis Elimination.

2. Dooley, M. S., J. Pharmacol. and Exper. Therap., 1921, xvii, 277. Evidence for the Presence in Digitalis of a Principle that is Eliminated Rapidly after Intravenous Injection into the Cat.

3. Weiss, S., and Hatcher, R. A., J. Am. Pharm. Assoc., 1923, xii, 26. Study of a Digitalis Body which is Eliminated Rapidly after its Intravenous Injection into the Cat.

4. Pardee, H. E. B., J. Am. Med. Assoc., 1919, lxxiii, 1822. Notes on Digitalis Medication. I. The Rate of Disappearance of Digitalis from the Body.

5. Pardee, H. E. B., N. Y. State J. Med., 1922, xxii, 131. The Continued Use of Digitalis.

6. Gold, H., and DeGraff, A. C., J. Am. Med. Assoc., 1928, xc, 1016. Studies on Digitalis in Ambulatory Cardiac Patients. I. The Use of Digitalis in the Cardiac Clinic. 